UDC 621.039.673

\title{
ST40 PROGRESS TOWARDS OPTIMIZED NEUTRON PRODUCTION
}

\author{
M. Gryaznevich., A. Nicolai, V. Chuyanov and Tokamak Energy Ltd. Team
}

\author{
Tokamak Energy Ltd., United Kingdom
}

ST40 tokamak, which is now operational, can be used as a prototype of a Compact Fusion Neutron Source. Such (CFNS) can be optimized for tritium production and complement a modular Fusion Power Plant. Recent results from ST40 are presented and options to optimize ST40 for neutron production are discussed.

Key words: spherical tokamak ST40, compact fusion neutron source (FNS).

DOI: $10.21517 / 0202-3822-2021-44-2-107-110$

\section{ПРОГРЕСС ОПТИМИЗАЦИИ ПРОИЗВОДСТВА НЕЙТРОНОВ В СФЕРИЧЕСКОМ ТОКАМАКЕ ST40}

\author{
М. Грязневич, А. Николаи, В. Чуянов и команда ООО «Токамак Энерджи»
}

ООО «Токамак Энерджи», Великобритания

Токамак ST40, который сейчас находится в эксплуатации, может быть использован в качестве прототипа компактного источника термоядерных нейтронов (КИТН). Такие КИТН могут быть оптимизированы для производства трития и стать частью модульной термоядерной электростанции. Представлены и обсуждаются последние результаты оптимизации ST40 по генерации нейтронов.

Ключевые слова: сферический токамак ST40, компактный источник термоядерных нейтронов.

\section{INTRODUCTION}

Tokamak Energy Ltd. is developing a modular approach to a fusion power plant [1]. In this new alternative route to fusion power, the economically feasible fusion power plant will consist of several low power modules. In all modular approaches, regular necessary maintenance is done offline in a module-to-module way, providing high availability of the power plant and lower maintenance cost. The approach saves time and resources needed for development, to improve reliability by the cheap reservation, to use economy of mass production. Our modular fusion plant will consist of several compact, low-power high-field spherical tokamak (ST) modules and auxiliary systems shared between them. This decreases the prototype costs (one module is actually a DEMO) and the fusion development risk [2]. The modular approach combines the advantages of the economy of scale for the conventional part of the plant and those of the economy of mass production for the fusion core and does not increase the plant's capital cost. At the same time, it permits to design a very efficient ST-based fusion power plant that allows for:

- high availability, due to reduced duration of the first wall change and maintenance. Modules can be serviced in turn, so electricity supply can be maintained;

- possibility for its units to share start-up (e.g., gyrotrons) and remote access facilities, as well as the hot cell for maintenance; ufacturers.

- establishing a sustainable supply chain, because the production of many small units is attractive to man-

Modules with acceptable fusion power and neutron wall loading should be in a narrow range of aspect ratios between $1.65<R / a<1.9$ [2]. Demonstration fusion module would aim to have a long pulse plasma operation with required fusion power and possible demonstration of tritium breeding, so it will be a compact Spherical Tokamak Fusion Neutron Source (ST FNS). The fusion module is not expected to be fully self-sufficient in tritium, and even in a full-scale power plant, the tritium self-sufficiency issue may be eased, as one of the modules will be customized to meet the tritium production need. A Compact Fusion Neutron Source (CFNS) based on a compact ST may act as a tritium breeder, if neutron output is maximized. Neutrons can also be produced via DD- and D- ${ }^{3} \mathrm{He}$ - (beam-plasma and beam-beam) reactions [3, 4], so there are ways to increase neutron production minimizing tritium consumption or even in DD. A CFNS based on a high-field ST may be also used for other non-electrical applications of fusion. 


\section{ST40 TOKAMAK AS A CFNS PROTOTYPE}

ST40 (design parameters: $R=0.4-0.6 \mathrm{~m}, R / a=1.6-1.8, I_{\mathrm{pl}}=2 \mathrm{MA}, B_{\mathrm{t}}=3 \mathrm{~T}$, elongation $k=2.5$, $\tau_{\text {pulse }} \sim 1-2 \mathrm{~s}, 3 \mathrm{MW}$ of Neutral Beam Injection (NBI), $2 \mathrm{MW}$ Electron Cyclotron Resonance Heating/Electron Bernstein Waves (ECRH/EBW), DD/DT operation) is a currently operational compact spherical tokamak (Fig. 1), proposed as a CFNS test prototype.
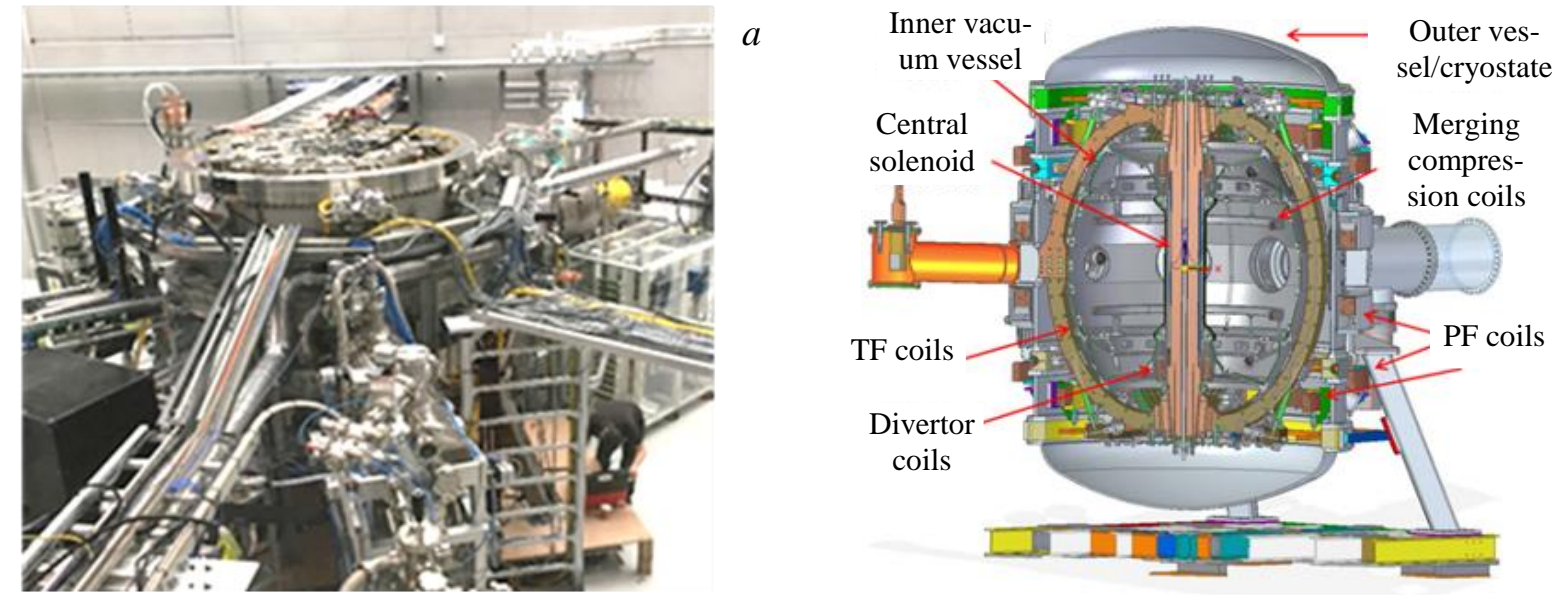

Fig. 1. ST40 tokamak: photo $(a)$ and sectional drawing $(b)$

Waveforms for a typical discharge, obtained in 2018 during initial operations, are presented in Fig. 2. A CCD visible light image and EFIT reconstruction at $30 \mathrm{~ms}$ are also shown. Plasma current $>0.5 \mathrm{MA}$ at $2 \mathrm{~T}$ toroidal field (TF), electron and ion temperatures in a several $-\mathrm{keV}$ range produced using merging-compression formation, solenoid-assisted ramp-up and $1 \mathrm{MW}$ of $25 \mathrm{kV} \mathrm{NB}$ heating, and densities up to $2 \times 10^{20} \mathrm{~m}^{-3}$ have been achieved in later experimental campaigns in 2019-2020. At the flat-top, measured $T_{i}$ increases with TF, in agreement with observations on other STs. However, on ST40, a sharp $T_{i}$ and $W_{\text {EFTT }}$ increase is observed at TF $>1-1.1 \mathrm{~T}$ (Fig. 3), which may suggest transition to a better confinement at higher TFs.

\begin{tabular}{|l|l|l|}
\hline & & \\
\hline
\end{tabular}
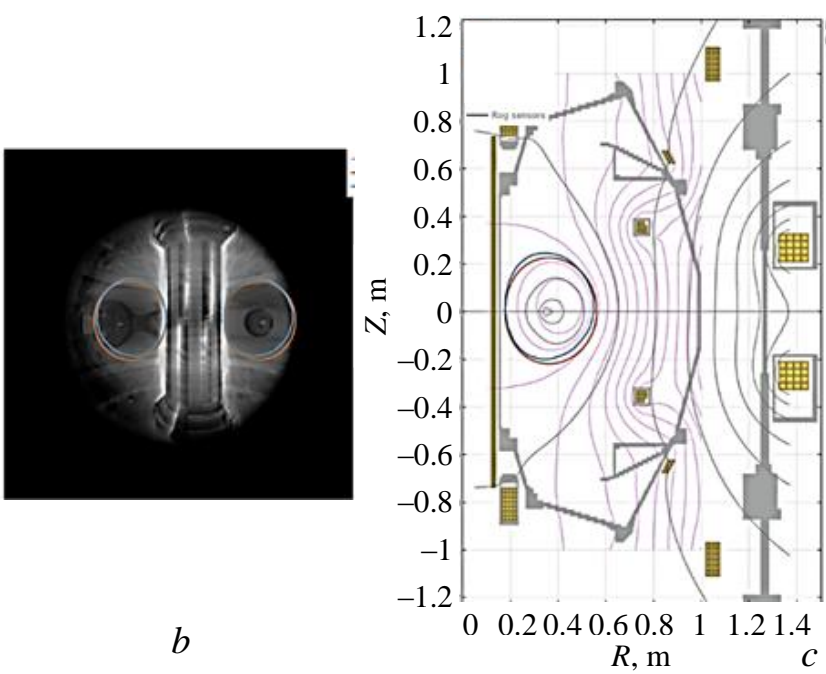

Fig. 2. Waveforms for a typical discharge with $B_{\mathrm{t}}=1.3 \mathrm{~T}(a)$, image in visible light $(b)$ and EFIT reconstruction at $t=30 \mathrm{~ms}(c)$
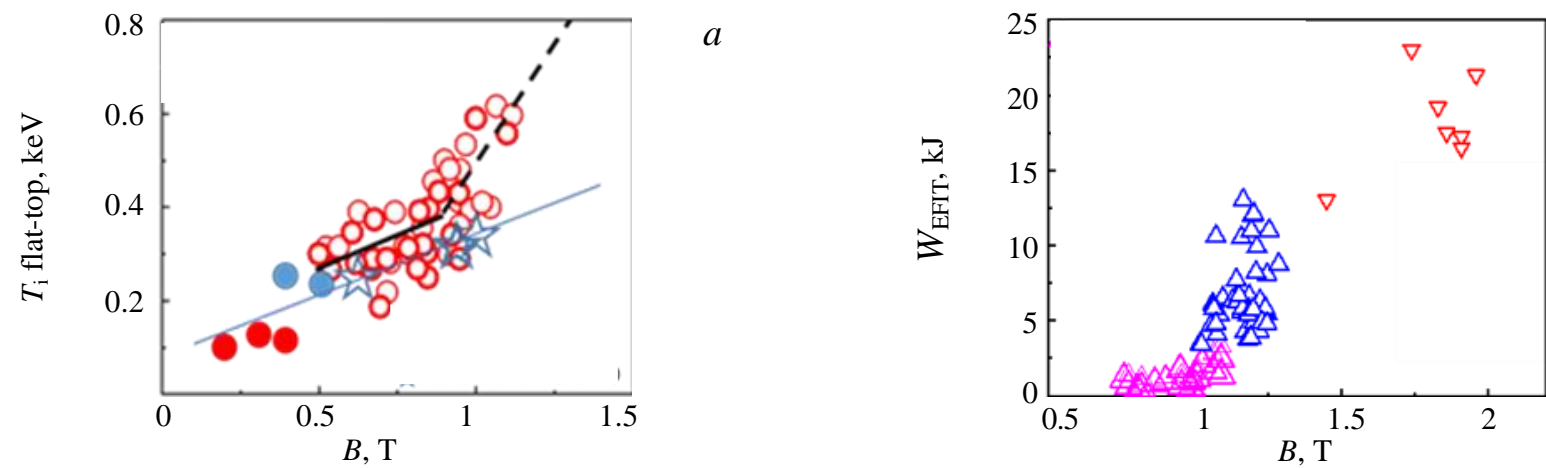

Fig. 3. $T_{i}$ measured with Doppler spectroscopy on ST40 in 2018 ( $\bigcirc-T_{\mathrm{i}}$ end of flat-top; $\bigcirc-T_{\mathrm{i}}$ mid of flat-top), and with NPA on START ( ) and Globus-M (O) against toroidal field, along with a predicted ion temperature assuming the Artsimovich formula ( $)$ ( $)(a)$; thermal energy $W_{\text {EFIT }}$ against toroidal field: $\Delta-W_{\text {EFIT }} 2018$ Prog0; $\Delta-W_{\text {EFIT }} 2019 \operatorname{Prog} 1 ; \nabla-W_{\text {EFIT }} 2019-20$ Prog2 (b) 


\section{OPTIMIZATION OF CFNS NEUTRON PRODUCTION PERFORMANCE}

There are several ways to use ST40 for optimizing neutron production. One is to optimize beam-plasma and beam-beam reactions to enhance the neutron yield. This can be done by accelerating fast ions injected by NBI to a significantly higher energy, increasing the efficiency of beam reactions to make neutron production more efficient [3]. The cross-section of these reactions increases strongly with fast ion energy, and if the latter grows to a mega-electron-volt level, neutron production from some reactions may increase many fold compared to reactions that occur in pure thermal Maxwellian plasma of a $10 \mathrm{keV}$ temperature range, Fig. 4.

In a high-field ST, the confinement of such highenergy ions may be significantly better than in conventional aspect ratio tokamaks or in STs with a low toroidal field, Fig. 5. The figure shows ion orbits for both trapped $(1 \mathrm{MeV})$ and freely passing cases, observed in a ST. It is clear from Fig. 5 that fast ions have smaller orbits and spend more time at the high-field side. These effects help reduce fast ion losses and enhance the efficiency of reactions on fast particles. Fig. 6 shows the results of ion distribution and neutron yield simulation with the NFREYA full-orbit Monte-Carlo code and the FIFPC Fokker-Planck code [5]. We use a $1 \mathrm{MW}, 50 \mathrm{keV}$ beam and accelerate $\mathrm{D}$ ions by Ion $\mathrm{Cy}-$ clotron Resonance Heating (ICRH) to $1 \mathrm{MeV}$. High neutron yield of up to $3.5 \times 10^{17} \mathrm{n} / \mathrm{s}$ can be expected, summarising DD beam-beam, beam-plasma, DDthermal and DT-thermal (tritium produced in the DDreaction). Several other approaches for fast ion accel-

$a$

Intermediate state (CRDROM. Cartesean)

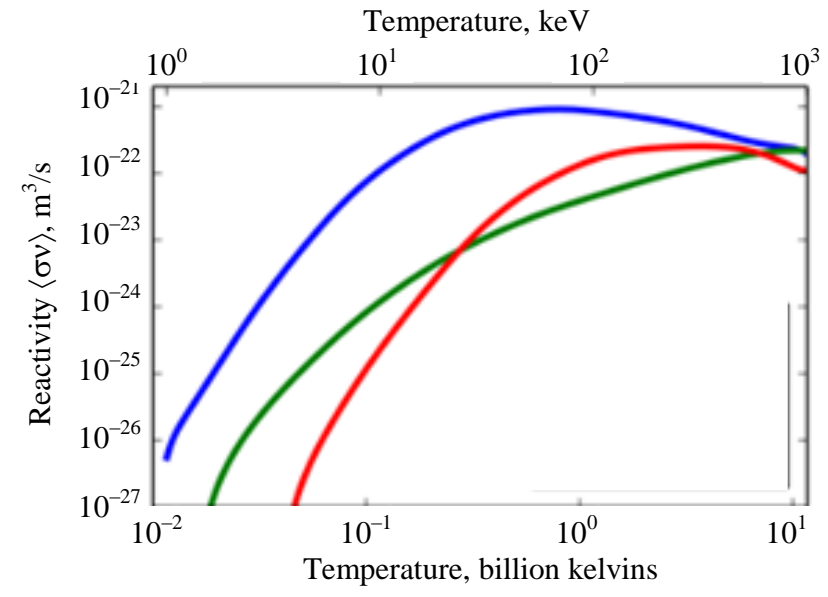

Fig. 4. Cross-sections of the primary fusion reactions: $--D$ $\mathrm{T} ;-\mathrm{D}-\mathrm{D} ;-\mathrm{D}-\mathrm{He}_{3}$
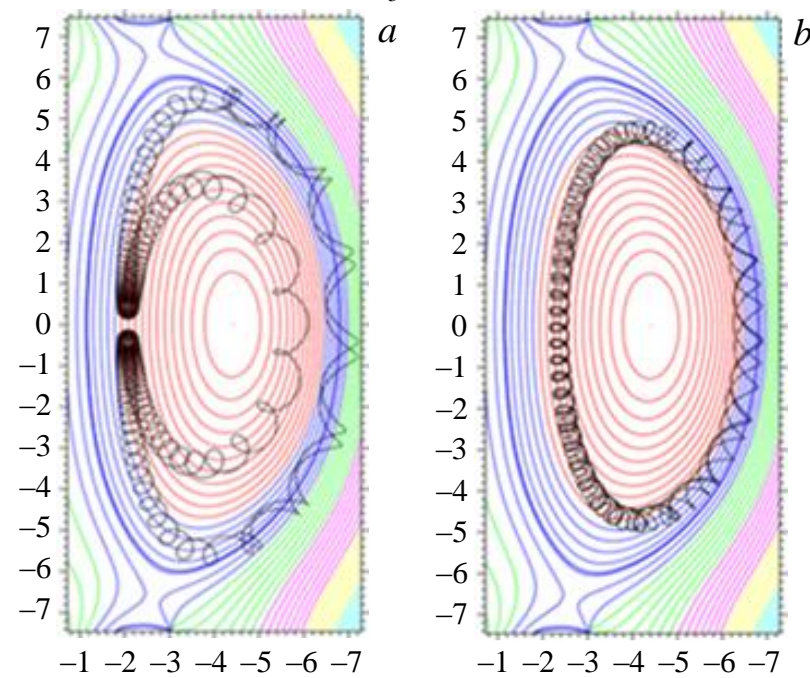

Fig. 5. Example of $1 \mathrm{MeV}$ trapped (a), and passing, ion orbits in a ST $(b)$

$b$
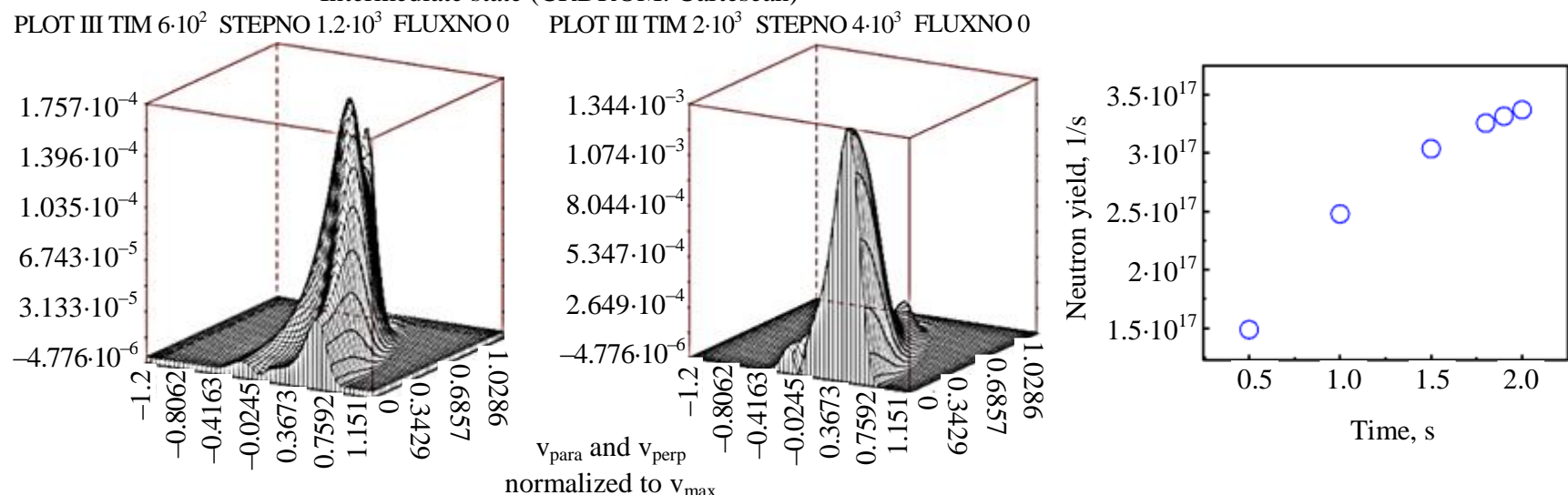

Fig. 6. Initial and final distribution of ions in velocity space: the background temperatures are $T_{e} / T_{i}=8.6 \mathrm{keV} / 6.4 \mathrm{keV}$, the density is $8 \cdot 10^{19} \mathrm{~m}^{-3}(a)$; neutron yield in time $(b)$

eration using ICRH can be considered [4].

Acceleration of the fast ion tail by ECRH with beating ECR waves has been attempted on tokamaks and other plasma devices [6]. While the ratio of each EC wave frequency to the ion cyclotron frequency is large 
(100 GHz range), the frequency difference can be near the ion cyclotron frequency (tens of $\mathrm{MHz}$ ), allowing the IC wave to heat plasma. The waves interact in a region close to ECR, where the efficiency is at its maximum. It may also be possible to transfer microwave power to energetic ions by parametric decay near the upper-hybrid resonance [6]. High-field side launch of EBW will be used on ST40 to test this in a spherical tokamak.

If $\mathrm{D}$ and $\mathrm{T}$ nuclei are polarized parallel to magnetic field and to each other, fusion reactivity may be increased by $50 \%$ [7]. Calculations suggest that deuteron polarization can enhance the DD-reaction by a factor of between 1.5 and 2 . Time to depolarize them by binary collisions is at least 5 times longer than the nuclear burning time. This will be of interest when a pure DD-fusion device is considered. The nuclei can be introduced into the fusion device by standard means, such as gas puffing, injection of energetic neutral beams or pellet injection.

\section{CONCLUSIONS}

Enhanced confinement of fast particles in STs opens up opportunities for boosting a high-field ST's neutron production efficiency. A CFNS based on a high-field ST may be used for tritium production and other nonelectrical applications of fusion. ST40 experiments contribute to the assessment of a high-field ST as a CFNS prototype.

\section{REFERENCES}

1. Gryaznevich M. et al. - J. of Physics: Conference Series, 2015, vol. 591, p. 012005.

2. Chuyanov V.A., Gryaznevich M.P. - Fusion Engineering and Design, 2017, vol. 122, p. 238.

3. Mantsinen M.J. et al. - Plasma Phys. Control. Fusion, 2003, vol. 45, p. A445.

4. Kirov K.K. et al. - AIP Conference Proceedings, 2020, vol. 2254, p. 030011.

5. Gryaznevich M., Nicolai A., Buxton P. - Nuclear Fusion, 2014, vol. 54, p. 104005.

6. Hansen S.K. et al. — Phys. Plasmas, 2019, vol. 26, p. 062102.

7. Kulsrud R.M. et al. — Nuclear Fusion, 1986, vol. 26, p. 1.

\section{AUTHORS}

Mikhail Petrovich Gryaznevich; mikhail.gryaznevich@tokamakenergy.co.uk

V. Chuyanov; Tokamak Energy Ltd. 173 Brook Drive, Milton Park, Oxon, OX14 4SD, United Kingdom valery.chuyanov@tokamakenergy.co.uk

A. Nicolai; Tokamak Energy Ltd. 173 Brook Drive, Milton Park, Oxon, OX14 4SD, United Kingdom

Received 15 January 2021

Revised 16 March 2021

Accepted 25 March 2021

Problems of Atomic Science and Technology Ser. Thermonuclear Fusion, 2021, vol. 44, issue 2, pp. 107-110 